Malaysian Journal of Fundamental and Applied Sciences

\section{Prioritization of Students Understanding in Rules of Differentiation using Fuzzy Soft Matrices and Lambda - max Method}

\author{
Samsiah Abdul Razak ${ }^{a, *}$, Aslina Omar ${ }^{b}$, Ainon Syazana Ab. Hamid", \\ Izni Syamsina Saaric
}

${ }^{a}$ Faculty of Computer and Mathematical Sciences, Universiti Teknologi MARA (UiTM),

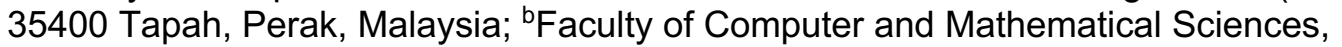
Universiti Teknologi MARA (UiTM), 81750 Pasir Gudang, Johor, Malaysia; ' ${ }^{\text {Faculty }}$ of Computer and Mathematical Sciences, Universiti Teknologi MARA (UiTM), 78000 Alor Gajah, Melaka, Malaysia

Abstract Calculus is one of the most important courses especially for undergraduate students in many fields of study. Some researchers have identified the causes of the high failure rate which includes lack of basic foundation of mathematics and basic concept of differentiation. Aside from that, the main problems that can be seen among students are the difficulty in identifying the type of function in differentiation and identifying the suitable method to solve a particular problem. There are three rules included in differentiation which are the Chain Rule, Product Rule and Quotient Rule. This study is conducted to examine the level of understanding of the students on the function and the derivative techniques after applying derivative game applications in this course. This paper is based on Fuzzy Analytic Hierarchy Process (Fuzzy AHP) which use fuzzy number in pair-wise comparison matrix. The prioritization of students' understanding in differentiation rules will then be measured by Fuzzy AHP using Lambda-max method. The highest among the three rules in differentiation will considered as a result. The findings of this study indicated that the highest score with 0.4700 is the Chain Rule. This study can help lectures to know the level or understanding among three rules in differentiation and lecturer well prepared their teaching materials in the classroom as well as to reduce the failure rate among students in this course.

Keywords: Derivative, Chain rule, Product rule, Quotient rule, Composite function, Rational function, Fuzzy soft set, Fuzzy soft matrix, Fuzzy analytic hierarchy process, Lambda - Max method.

\section{Introduction}

Calculus I is a core requirement for any sciences university that have mathematics as a major. It is the first in a sequence of courses designed to provide the skills and concepts required to further their studies in mathematics, physics, computer science and engineering (Aspinwall \& Miller, 2013). The curriculum of Calculus I cover the following main concepts: limits of functions, continuity of functions, the derivative of a function, graphs of functions, and other applications to the derivative (Habre \& Abboud, 2006).

One of the most important and fundamental concepts in calculus is the concept of function. Calculus requires a high level of conceptual understanding but many students struggle to understand the 
derivation itself (Parameswaran, 2007).

Difficulty to succeed in calculus is one of the main reasons students cannot endure in engineering. In fact, historically, calculus has served as a filter in many engineering schools. Engineering and math departments at various universities have worked together to address this problem (Hensel, Lowery, \& Sigler, 2008).

\section{Literature Review}

\section{Calculus}

There are several approaches in teaching calculus which include introducing additional cooperative learning and problem-solving opportunities for engineering students taking calculus (Hart, Holloman, \& Connor, 1995); creating learning communities based on math placement so students can help and encourage each other (Tsang, Halderson, \& Kallen, 2007); removing pre-requisites to permit students to take Calculus 1 in their second semester and still progress on schedule in their engineering curricula (Ohland, Yuhasz, \& Sill, 2004); redefining how engineering math is taught and creating a hands-on, application-oriented approach addressing only topics relevant to the core engineering courses (Klingbeil, Rattan, Raymer, Reynolds, Mercer, Kukreti, \& Randolph, 2007); and instituting an "early warning" system with optional "intensive pre-calculus" mid-semester math tracks for struggling students (Koch, 2007).

Behavior is one of the factors of failure rates among the students, where almost more than $30 \%$ above student fails in calculus every semester (Shamsatun et al, 2017). The others reseacher say that, difficulty succeeding in claculus is one of the essential reason undersudies exchange ou of engineering course (Robinson, 2008). Failure in calculus in one of the reason engineering school and math departments in a assortment of universities have worked together to address the problem.

Many of these approaches have been successful in increasing students's score in calculus. Each university environment has a unique set of characteristics, policies and culture. What works effectively in one university, may not be easily accomplished or as effective in another.

\section{Fuzzy AHP}

Analytical Hierarchy Process (AHP) introduced by Saaty (1980) is one of the most and widely applied methods in determining criteria weight, where it can be used as an input in ranking alternatives due to its flexibility to cater the various kinds of multi criteria decision making (MCDM) method (Liu, Kwon \& Kang, 2007). AHP integrates the expert opinions and evaluates score and device the complex decisionmaking method into a simple elementary hierarchy system. In addition to this, AHP is easy to compute and it can effectively cater both qualitative and quantitative data. Besides that, it provides a specific mechanism for checking the consistency of the evaluation measures and alternative decided by a decision maker. Thus, it can reduce bias in decision making (Ariff, Salit, Ismail \& Nukman, 2008; Lixiong, Liang \& Minzhong, 2010). In AHP, all the evaluation method among the criteria will be analyzed in pairwise comparison.

However, AHP's inability to adequately handle the evaluations uncertainty and imprecision in which the human judgment is represented in fuzzy numbers (Wang, C.H. Cheng \& H.K. Cheng, 2009). In order to overcome this shortcoming, fuzzy sets can be synchronized with the pair - wise comparison as an extension of AHP. In 1983, Laarhoven and Pedrycz were the first to extend the concept of AHP to Fuzzy AHP for presented in effectively the uncertainty and vagueness from subjective performance and the experiences of decision maker in solving the hierarchy problem. Natasa and Ziwojin (2016, and 2017) applied Fuzzy AHP for decision making in the construction industry and realization of construction projects and also apply in ranking and selection of alternatives related to the project realization. Samsiah et al. (2011, 2012, and 2017) utilized fuzzy AHP (Lambda-Max Method) in determining the criteria weight for the main and sub-criteria in solving the group decision making problem.

This research utilized the Fuzzy AHP (Lambda-Max Method) to prioritize the understanding of students in Chain Rule, Product Rule and Quotient Rule in differentiation after finish answer all the question in the derivatives games. It is because Fuzzy AHP method is easy to compute and can provide a direct and definite value by expert and do not reflect the human thinking style. 


\section{Methodology}

\section{Triangular Fuzzy Number}

The positive triangular fuzzy numbers can be defined as 3-tuplet denotes the least possible value, the most possible value and the largest possible value that describes fuzzy event. All these parameters indicate the fuzzy relative importance and respectively with the membership function defined as:

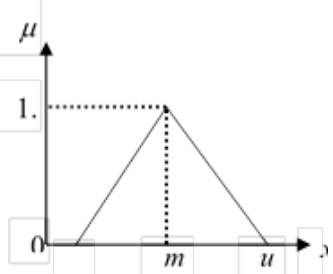

$$
\mu_{\widetilde{M}}(x)= \begin{cases}0 & x \prec l \\ \frac{x-l}{m-l} & l \leq x \leq m \\ 1 & x=m \\ \frac{u-x}{u-m} & m \leq x \leq u \\ 0 & x \succ u\end{cases}
$$

with $-\infty<l \leq m \leq u<\infty$

Fig. 1 The membership functions of triangular fuzzy number

$$
\tilde{M}=(l, m, u) \text {. }
$$

\section{Lambda-Max Method}

According to Buckley and Csutora (2001), the fuzzy positive reciprocal matrix with triangular fuzzy numbers can be defined as:

$\widetilde{K}^{S}=\left[r_{i j}\right]_{m}^{S}$ where,

$\widetilde{K}^{s}$ : a positive reciprocal matrix of decision maker $s$;

$\tilde{r}_{i j}$ : relative importance between decision elements $i$ and $j$;

$\tilde{r}_{i j}(1,1,1), \forall i=j ;$ and

$\tilde{r}_{i j}=\frac{1}{\widetilde{r}_{j i}}, \forall i, j, \ldots, n$

The procedure of lambda-max method is as follows:

Step 1: $\quad$ Apply $\alpha-c u t$. To obtain the positive matrix of decision maker $R$, let $\alpha=1, \widetilde{K}_{m}^{s}=\left[\widetilde{r}_{i j}\right]_{m}^{s}$, and let $\alpha=0$ to obtain the lower bound and upper bound positive matrices of decision maker s, $\widetilde{K}_{l}^{s}=\left[\widetilde{r}_{i j}\right]_{l}^{s}$ and $\widetilde{K}_{u}^{s}=\left[\widetilde{r}_{i j}\right]_{u}^{s}$. Calculate weight vector, based on the weight calculation procedure in $\mathrm{AHP}, W_{m}^{s}=\left(w_{i}\right)_{m}^{s}, W_{l}^{s}=\left(w_{i}\right)_{l}^{s}$, and $W_{u}^{s}=\left(w_{i}\right)_{u}^{s}, i=1,2, \ldots, n$.

Step 2: In order to minimize the fuzziness of the weight, choose two constants, $M_{l}^{s}$ and $M_{u}^{s}$, as follows;

$$
\begin{aligned}
& M_{l}^{s}=\min \left\{\frac{w_{i m}^{s}}{w_{i l}^{s}}\right\}, 1 \leq i \leq n \\
& M_{u}^{s}=\min \left\{\frac{w_{i m}^{s}}{w_{i u}^{s}}\right\}, 1 \leq i \leq n
\end{aligned}
$$

The upper bound and lower bound of the weight a defined as:

$$
W_{i l}^{*}=M_{l}^{s} w_{i l}^{s}
$$

$W_{i u}^{*_{s}}=M_{u}^{s} w_{i u}^{s}$, so the lower bound and upper bound weight vectors are $\left(w_{i}^{*}\right)_{l}^{s}$ and $\left(w_{i}^{*}\right)_{u}^{s}, i=1,2, \ldots, n$.

Step 3: By combining the upper bound, the middle bound and the lower bound weight vectors, the fuzzy weight matrix for decision maker ${ }^{S}$ can be obtained and is defined as:

$$
\widetilde{W}_{i}^{s}=\left(w_{i l}^{*_{s}}, w_{i m}^{*_{s}}, w_{i u}^{*_{s}}\right), \quad i=1,2, \ldots, n \text {. }
$$


Step 4: Integrate the opinion of decision makers by applying the geometric mean. The geometric mean is used to combine the fuzzy weight of each decision makers and is defined as follows:

$\widetilde{\bar{W}}_{i l}^{K}=\left(\tilde{W}_{i l}^{1} \otimes \tilde{W}_{i l}^{2} \otimes, \ldots, \otimes \tilde{W}_{i l}^{k}\right)^{1 / k}$,
$\widetilde{\bar{W}}_{i m}^{K}=\left(\tilde{W}_{i m}^{1} \otimes \tilde{W}_{i m}^{2} \otimes, \ldots, \otimes \tilde{W}_{i m}^{k}\right)^{1 / k}$,
$\widetilde{\bar{W}}_{i u}^{K}=\left(\tilde{W}_{i u}^{1} \otimes \tilde{W}_{i u}^{2} \otimes, \ldots, \otimes \tilde{W}_{i u}^{k}\right)^{1 / k}$,

Then the fuzzy weights $\widetilde{\bar{W}}_{i}^{K}$ of each criterion are

${\widetilde{W_{i}}}_{i}^{K}=\left(\widetilde{\bar{W}}_{i l}^{K}, \widetilde{\bar{W}}_{i m}^{K}, \widetilde{\bar{W}}_{i u}^{K}\right)$,

Step 5: Calculate local weights and global weight with repetition from step 1 until step 3 . We use the following linguistic variables and the image of its membership function is shown in Table 1:

Table 1 Triangular Fuzzy conversion table: importance/preference of one alternative over another

\begin{tabular}{lcc} 
Linguistic Scale & $\begin{array}{c}\text { Triangular Fuzzy } \\
\text { Scale }\end{array}$ & $\begin{array}{c}\text { Triangular Fuzzy } \\
\text { Reciprocal Scale }\end{array}$ \\
\hline Just Equal & $(1,1,1)$ & $(1,1,1)$ \\
\hline Equally important & $(1 / 2,1,3 / 2)$ & $(2 / 3,1,2)$ \\
\hline Weakly more important & $(1,3 / 2,2)$ & $(1 / 2,2 / 3,1)$ \\
\hline Strongly more important & $(3 / 2,2,5 / 2)$ & $(2 / 5,1 / 2,2 / 3)$ \\
\hline Very strongly more important & $(2,5 / 2,3)$ & $(1 / 3,2 / 5,1 / 2)$ \\
\hline Absolutely more important & $(5 / 2,3,7 / 2)$ & $(2 / 7,1 / 3,2 / 5)$ \\
\hline
\end{tabular}

Triangular Fuzzy conversion scale (Bozbura \& Beskese, 2006)

\section{Data Collection}

The data was obtained from a set of questionnaires distributed among Calculus 1 (MAT183) students from UiTM Perak, Tapah Branch. The questionnaires were distributed after all the students already played the application games of derivative techniques. In this applications games students need to identify the type of equation and then identify which rules they need to used in solving the question either by using Chain Rule, Product Rule or Quotient Rule. They need to finish all the question in this games, at the end the applications of derivatives will show the total mark that they will get for every types of rules.

They are student in a class of Calculus 1 (MAT 183), considered as decision makers in this study. 52 out of 75 students completed the questionnaire and the input from them were analyzed using Lambda-Max Method in fuzzy AHP by using Microsoft Excel 2013. They were required to give their opinion on the evaluation of pair-wise comparison of the criteria included in the research, there is Chain Rule (CR), Product Rule (PR) and Quotient Rule (QR).

\section{Findings}

The 52 students of MAT 183 were the decision makers and were labeled as $\mathrm{DM}_{1}, \mathrm{DM}_{2}, \mathrm{DM}_{2}, \cdots, \mathrm{DM}_{52}$. They were selected to perform the evaluation of fuzzy pair-wise comparison for Chain Rule, Product Rule and Quotient Rule with to the Effectiveness of the Application of Derivatives Games. From the pair-wise comparison of the decision makers for each criterion, evaluation matrices are formed into triangular fuzzy number as in Table 2 to Table 5. 
Table 2 Fuzzy Pair-wise comparison for the three rule of differentiation given by $\mathrm{DM}_{1}$

\begin{tabular}{lccc}
\hline & Chain Rule & Product Rule & Quotient Rule \\
\hline Chain Rule & $(1,1,1)$ & $\left(1, \frac{3}{2}, 2\right)$ & $\left(\frac{1}{2}, 1, \frac{3}{2}\right)$ \\
\hline Product Rule & $\left(\frac{1}{2}, \frac{2}{3}, 1\right)$ & $(1,1,1)$ & $\left(\frac{1}{2}, \frac{2}{3}, 1\right)$ \\
\hline Quotient Rule & $\left(\frac{2}{3}, 1,2\right)$ & $\left(1, \frac{3}{2}, 2\right)$ & $(1,1,1)$ \\
\hline
\end{tabular}

Table 3 Fuzzy Pair-wise comparison for the three rules of differentiation given by $\mathrm{DM}_{2}$

\begin{tabular}{lccc}
\hline & Chain Rule & Product Rule & Quotient Rule \\
\hline Chain Rule & $(1,1,1)$ & $\left(1, \frac{3}{2}, 2\right)$ & $\left(\frac{1}{2}, 1, \frac{3}{2}\right)$ \\
\hline Product Rule & $\left(\frac{1}{2}, \frac{2}{3}, 1\right)$ & $(1,1,1)$ & $\left(\frac{1}{2}, \frac{2}{3}, 1\right)$ \\
\hline Quotient Rule & $\left(\frac{2}{3}, 1,2\right)$ & $\left(1, \frac{3}{2}, 2\right)$ & $(1,1,1)$ \\
\hline
\end{tabular}

Table 4 Fuzzy Pair-wise comparison for the three rule of differentiation given by $\mathrm{DM}_{3}$

\begin{tabular}{lccc}
\hline & Chain Rule & Product Rule & Quotient Rule \\
\hline Chain Rule & $(1,1,1)$ & $\left(\frac{2}{3}, 1,2\right)$ & $\left(\frac{2}{3}, 1,2\right)$ \\
\hline Product Rule & $\left(\frac{1}{2}, 1, \frac{3}{2}\right)$ & $(1,1,1)$ & $\left(\frac{1}{2}, 1, \frac{3}{2}\right)$ \\
\hline Quotient Rule & $\left(\frac{1}{2}, 1, \frac{3}{2}\right)$ & $\left(\frac{2}{3}, 1,2\right)$ & $(1,1,1)$ \\
\hline
\end{tabular}

Table 5 Fuzzy Pair-wise comparison for the three rule of differentiation given by $\mathrm{DM}_{52}$

\begin{tabular}{lccc}
\hline & Chain Rule & Product Rule & Quotient Rule \\
\hline Chain Rule & $(1,1,1)$ & $\left(\frac{3}{2}, 2, \frac{5}{2}\right)$ & $\left(\frac{3}{2}, 2, \frac{5}{2}\right)$ \\
\hline Product Rule & $\left(\frac{2}{5}, \frac{1}{2}, \frac{2}{3}\right)$ & $(1,1,1)$ & $\left(\frac{3}{2}, 2, \frac{5}{2}\right)$ \\
\hline Quotient Rule & $\left(\frac{2}{5}, \frac{1}{2}, \frac{2}{3}\right)$ & $\left(\frac{2}{5}, \frac{1}{2}, \frac{2}{3}\right)$ & $(1,1,1)$ \\
\hline
\end{tabular}

The Lambda -max method (Csutora \& Buckley, 2001) was used to calculate the prioritization the rule of differentiation after using the application of derivatives game given by students. To compute the calculation, there are several steps as mention in section 2.3.The prioritization of Differentiation Rule is shown in Table 7 and each of the rules are transformed into the fuzzy number as shown in Figure 2.

Table 6 The prioritization of Differentiation Rule in Triangular Fuzzy Number.

\begin{tabular}{llll}
\hline Chain Rule & 0.4392 & 0.473 & 0.5028 \\
\hline
\end{tabular}




\begin{tabular}{llll}
\hline Product Rule & 0.2358 & 0.247 & 0.2580 \\
\hline Qoutient Rule & 0.2667 & 0.287 & 0.3015 \\
\hline
\end{tabular}

By using the Average method, the prioritization of differentiation will be converted in Crisp value as shown in Table 7.

Table 7 The prioritization of Three Differentiation Rule

\begin{tabular}{ll}
\hline Chain Rule & 0.4700 \\
\hline Product Rule & 0.2461 \\
\hline Quotient Rule & 0.2839 \\
\hline
\end{tabular}

The result of the questionnaire survey on the students' level of understanding among Chain Rule, Product Rule and Quotient Rule in Derivative topic after using Derivatives games were calculated using LambdaMax Method and is shown in Table 7. Based on the result in Table 7, the highest score with 0.4700 is Chain Rule. It shows that students have a better understanding about Chain Rule followed by Quotient Rule and Product Rule.

\section{Conclusion and Recommendation}

This investigate is fundamentally important particularly to the teachers and students themselves. It will help students to know the level of understanding between the three rules of derivatives. At the same time, this research will also help lecturers in planning their strategies to cater the differention topic in Calculus 1 in order to effectively contribute to students' learning. We implemented the Lambda-Max method in prioritize the students understanding in a rule of derivatives. The results show that the Chain Rule with 0.4700 is the highest understanding in derivatives rules followed by Quotient Rule with 0.2839 and Product Rule 0.2461 .

\section{Acknowledgement}

The authors would like to gratefully acknowledge financial support from Universiti Teknologi Mara (UiTM) through the ARAS grant (File No: 600-IRMI/DANA 5/3/ARAS (0171/20).

\section{References}

Samsiah.R, \& Daud.M. 2012. An Application of Soft Matrices in Group Decision Making Problems (Aplikasi Matrik Lembut dalam Masalah Pembuatan Keputusan Secara Berkumpulan), Menemui Matematik (Discovering Mathematics). Vol. 34 No. 1, pp.33- 39.

Samsiah.R,\& Daud.M. 2013. A Decision Making method using Fuzzy Soft Sets. Malaysian Journal of fundamental and Applied Sciences, Vol. 9, No.2 99-104

S.A.Razak, Daud.M, \& Ini Imaina.A, 2017, A Group Decision Making Problem Using Hierarchical Based Fuzzy Soft Matrix International Journal of Advanced and Applied Sciences, 4(10), pp 26-3.

Natasa.P \& Zivojin.P. 2017. Application of fuzzy AHP for ranking and selection of alternatives in construction project management. Journal of civil engineering and management, issn 1392-3730 / eissn 1822-3605,2017 volume 23(8): pp 1123-1135

Natasa.P \& Zivojin.P. 2016 Application of fuzzy AHP method based on eigenvalues for decision making in construction industry. ISSN 1330-3651 (Print), ISSN 1848-6339 (Online)

Aspinwall, L., \& Miller, L. D. 2013. 000f7c1be7987fea1fb5ca4dc2cbca59.pdf. Journal of Intructional Psychology.

Habre, S., \& Abboud, M. 2006. Students' conceptual understanding of a function and its derivative in an experimental calculus course. Journal of Mathematical Behavior, 25(1), 57-72. https://doi.org/10.1016/j.jmathb.2005.11.004

Hensel, R., Lowery, A., \& Sigler, J. R. 2008. Breaking the Cycle of Calculus Failure: Models of Early Math Intervention to Enhance Engineering Retention. ASEE Annual Conference and Exposition.

Parameswaran, R. 2007. On understanding the notion of limits and infinitesimal quantities. International 
Journal of Science and Mathematics Education. https://doi.org/10.1007/s10763-006-9050-y

Hart, B.G.; Holloman, T.I.; Oapos; Connor, C.A. A Calculus Retention Program for Students at Risk in Engineering. Frontiers in Education Conference, 1995. Proceedings, 1995.

Tsang, E., Halderson, C., Kallen, K. Work In Progress - Western Michigan University's Effort to Increase Retention of First-Time, First-Year Engineering and Applied Sciences Students. 37th ASEE/IEEE Frontiers in Education Conference. October 10-13, 2007, Milwaukee, WI.

Ohland, M.W., Yuhasz, A.G., Sill, B.L. Indentifying and Removing a Calculus Prerequisite as a Bottleneck in Clemson's General Engineering Curriculum. Journal of Engineering Education, July 2004. pp. 253-257.

Klingbeil, N., Rattan, K., Raymer, M., Reynolds, D., Mercer, R., Kukreti, A. and Randolph, B., "A National Model for EngineeringMathematics Education," Proceedings 2007 ASEE Annual Conference \& Exposition, Honolulu, HI, 2007.

Koch, D. "Intervention Strategy for Improving Success Rates in Calculus. Seminar on Teaching Mathematics". Department of Mathematics, University of Michigan. November 12, 2007.

Ahmad, N.A., Shafaruniza, M., Muhammad, Y.Y., Haslenda, Y., Mohammad, N.A., Chu. H.H.,"Factors Related to Students' Performance in Calculus". Journal of Applied Environmental and Biological Sciences, 2017. pp .51-56.

Robin, H., Andrew L., J.Ryan, S.," Breaking the cycle of calculus failure: models of Early math intervention to enhance engineering retention" American Society for Engineering, 2008. 